Article

\title{
Vehicle-Related Flood Fatalities in Texas, 1959-2019
}

\author{
Zhongyu Han and Hatim O. Sharif*(D) \\ Department of Civil and Environmental Engineering, University of Texas at San Antonio, San Antonio, \\ TX 78249, USA; joeyhan2015@outlook.com \\ * Correspondence: hatim.sharif@utsa.edu; Tel.: +1-210-458-6478
}

Received: 24 August 2020; Accepted: 13 October 2020; Published: 16 October 2020

\begin{abstract}
Texas has the highest number of flood fatalities and vehicle-related flood fatalities in the United States. This study provides a detailed analysis of vehicle-related flood fatalities in Texas from 1959 to 2019. The data was compiled from the Storm Data publication maintained by the National Weather Service and includes demographics of the victims, dates, flood types, roadway types, and fatality location. There were 570 vehicle-related flood fatalities during the study period, with almost all fatal accidents resulting in one fatality. These fatalities represent $58 \%$ of total flood fatalities. The spatial analysis reveals that most counties with high vehicle-related flood fatalities are clustered in Flash Flood Alley. These counties accounted for over $80 \%$ of the fatalities. The annual distribution of these fatalities follows a statistically significant decreasing trend. Monthly distribution of vehicle-related fatalities follows that of rainfall in the Flash Flood Alley, with flash floods causing $61 \%$ of all vehicle-related flood fatalities. Night was the time of the day when the most vehicle-related deaths occurred. Males accounted for $63 \%$ of the fatalities and the age group of 20-29 was the most affected. The study discusses how the results can be used to increase awareness of flood hazards, used as input into state and regional disaster mitigation plans, and help tailor education and outreach programs.
\end{abstract}

Keywords: vehicles; flood; fatalities; Texas; flash flood alley; hazards

\section{Introduction}

Several natural disasters such as lightning, hurricanes, floods, and heat waves cause huge human and economic losses every year across the globe. In the 20th century, floods alone resulted in the death of more than 6.62 million people around the world [1]. French et al. [2] and Dittmann [3] reported that flooding was the main event causing weather-related deaths in the United States. Almost $80 \%$ of the global 6500 disaster events between 1980 and 2016 that caused fatalities were hydrometeorological [4]. Flooding is the primary hydrometeorological disaster type that is responsible for hundreds of fatalities across the globe every year (e.g., Chowdhury et al., 1993; Gerritsen, 2005; Borded and Cutter, 2008; Hahn et al., 2017) [5-8]. According to the National Weather Service (NWS), floods caused the second highest number of natural disaster deaths after heat waves in the United States [9]. Different circumstances lead to fatalities during a flooding event. Most flood deaths occur through drowning [10]. Studies that can focus on certain types of floods that affect a specific region can improve understanding of the hazards and offer new insight to guide investment of resources for mitigation. Terti et al. [11] studied the circumstances of more than 1000 flash flood fatalities across the US and found that the fatality circumstances have certain characteristics related to season, time of the day, duration of the flood, location, and age and gender groups. Petrucci et al. [12] studied flood mortality in Mediterranean countries over a 36-year period (1980-2015) and reported that fatalities were increasing, they occurred mostly outdoors, and most of them occurred to people being dragged by water/mud or who were travelling in a vehicle. Diakakis and Deligiannakis [13] examined flood 
fatalities in Greece from 1970 to 2010 and found that vehicle-related deaths are the most common type of incident, with drowning being the most common etiology of death.

Vehicle-related flood death was the dominant type among all circumstances in the US. Hamilton et al. [14] reported that more than half of flood-related deaths were caused by driving through floodwaters. They found that past living experience, individual perceptions of the floodwater hazard, and social and environmental circumstances are the main factors impacting a person's decision on whether to drive through floodwaters. Drobot et al. [15] also reported that more than half of all flood fatalities in the United States are vehicle-related, mainly because people who do not treat flood warnings seriously and people who have not experienced floods drive into floodwaters. Ashley and Ashley [16] asserted that human behavior was a major culprit in flood deaths and that $63 \%$ of flood fatalities recorded with occurrence circumstance are vehicle-related. French et al. [2] found that $42 \%$ of drowning deaths were vehicle-related during a study from 1969 to 1981. Zevin [17] reported that $40 \%$ of flash-flood fatalities were related to vehicles or pedestrians crossing streams. Mooney [18] found that over half of flood fatalities with a known circumstance of occurrence happened in vehicles. Terti et al. [11] found that more than $60 \%$ of the 1075 flash flood fatalities reported from 1996 to 2014 across the United States were related to vehicles involving mainly males. This study found that human vulnerability depends on the social and natural factors of the flash flood; e.g., fatalities related to inundation of permanent buildings were most commonly associated with longer duration events and impacted the elderly, while the young were victims of outdoor activities during short-lived flash floods. In addition to human and social vulnerabilities, Doocy et al. [19] reported that urbanization, population density, terrain, and storm characteristics are also factors that contribute to flood risk levels. Flood fatality factors that influence human impacts were rural areas, short duration events, small catchment sizes, vehicles, and events that occurred during times with reduced visibility [20].

Ahmed et al. [21] examined the vehicle-related flood fatalities in Australia from 2001 to 2017. It was found that $83 \%$ of vehicle-related flood deaths happened when people drove through cross creeks, bridges, or causeways that flooded by rapidly rising floodwater. Drowning was the main category of vehicle-related deaths, resulting in 1.3 fatalities per incident. Half of the incidents occurred at night and $54 \%$ of the incidents had only the driver in the vehicle. Age and gender data were identified for drivers and passengers and males significantly outnumbered females. Jonkman and Vrijling [22] reported that individual behavior and vulnerability are the main factors in flood fatalities. Kellar and Schmidlin [23] conducted a study on vehicle-related flood fatalities in the United States from 1995 to 2005 and found that more than half of flood fatalities caused by flash floods are vehicle-related. They also found that males were overrepresented by far, especially among those older than 40 , in all vehicle-related flood fatalities. The Texas Hill Country was identified as the area with the highest vehicle-related flood fatalities. Vehicle-related flood fatalities could occur at bridges, low water crossings, ditches/culverts, and viaducts or underpasses. Jonkman and Kelman [10] reported that males were more vulnerable to floodwaters because they were more likely to be involved in unnecessary high-risk behaviors. They also reported that vehicle-related flood deaths occurred most frequently when people attempted to drive across flooded bridges, streams, and roads and these deaths occurred among all phases of flood events (i.e., onset, during, and shortly after). Coates [24] investigated flood fatalities in Australia from 1788 to 1996 and found that males were more likely to be involved in risky behaviors than females when faced with floodwaters. About $38.5 \%$ of all flood fatalities with reported details happened across flooded creeks, bridge, and roads and $31.5 \%$ of all flood fatalities were people trapped in a building or camp. Adults and the elderly tend to be more vulnerable, especially in light of the growth of the elderly population in most countries [25]. When people are trapped inside vehicles in floodwaters, moving waters may sweep vehicles off the road, depending on the water depth and velocity, which are usually underestimated by drivers [26]. The deeper the floodwater is, the less force or velocity of floodwater is needed to tip a person over. Some people try to escape from their trapped vehicles but are swept away or killed by floating objects [27]. 
Compared to other states in the USA, Texas has been reported to have the highest number of flood fatalities in all studies, e.g., [16,28]. Ashley and Ashley (2008) reported a total of 4586 flood fatalities in the USA from 1959 to 2005. Texas (760) had, by far, more flood fatalities than any other state [16]. Sharif et al. [28] had similar results, indicating that Texas had 840 flood fatalities from 1959 to 2008. Kellar and Schmidlin [23] found that Texas is the state with the most storm events (60) and most vehicle-related flood fatalities (107) from 1995 to 2005. Ashley and Ashley [16] found that the geographic features of Texas lead to a large number of flood fatalities in Texas. Texas is the second largest state in the USA by area $\left(695,662 \mathrm{~km}^{2}\right)$ and population (approximately 29.90 million in 2020). Floods in Texas caused by tropical storms and inland storms relate to different weather patterns such as the North American Monsoon system and movements on cold and warm fronts. The geographic location of the Balcones Escarpment, which consists of a series of cliffs dropping from the Edwards Plateau to the Balcones Fault Line, enhances the formation and increases the efficiency of storms in central Texas. The Gulf of Mexico in the south to the Rocky Mountains in the northwest contribute to the creation of storms capable of producing large amounts of rainfalls. The Texas Hill Country, located on the edge of the Escarpment, is also susceptible to flash floods due to the steep slopes, the very thin topsoil, and large areas of exposed bedrock. Another reason for enhanced runoff in the region is the existence of the highly urbanized corridor extending between the major metropolitan areas Dallas-Fort Worth and San Antonio. This region is known as "Flash Flood Alley". It includes counties with the fastest population growth rates in Texas (Figure 1). Construction of large, expensive structures at road-stream crossings in this region is not feasible because there are thousands of these crossing and they stay dry all the time except for occasional storm events. Drainage at these crossings is through culverts and over-the-road flow. Low water crossings throughout Texas, especially in the Hill Country, contribute to road flooding, which poses a significant risk to drivers during flooding conditions $[29,30]$.

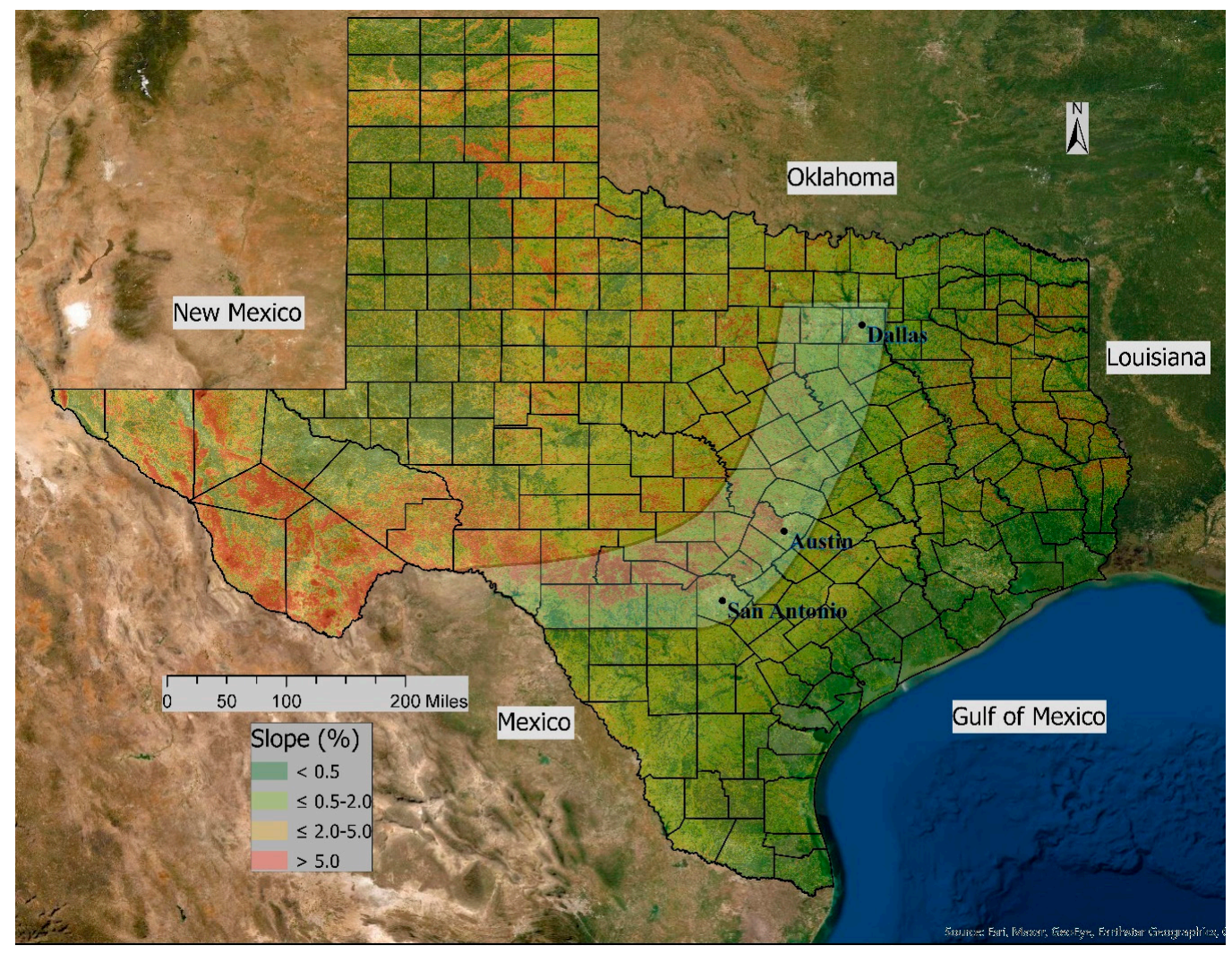

Figure 1. The Flash Flood Alley with slopes shown in the background (steepest slopes are red to orange). 
Motivated by these findings, this study investigated the vehicle-related flood fatalities in Texas from 1959 to 2019. We will examine, in detail, specific factors within a state that are associated with the highest flood mortality numbers in the US, including vehicle-related fatalities. Moreover, recent years have seen an increase in flood fatalities in Texas, especially in the Houston area. As flood mitigation efforts need to include measures to address risky behavior, we hope that the analysis will contribute to building models of flood resilience for the communities of Texas. The analysis takes into account demographics (age and gender), temporal distributions (annual vehicle-related flood fatalities, month, time of the day), flood types, roadway types, and spatial distribution. The limitations of the database used are described in the summary and conclusions section. The paper discusses factors that may influence the high rate vehicle-related flood fatalities in Texas, compared to other states, and provide information that can help reduce this rate.

\section{Data and Methods}

Storm Data is a database maintained by the National Climatic Data Center (NCDC). It includes monthly reports detailing the impacts of severe weather events. The National Weather Service (NWS) started releasing the predecessor of Storm Data, Climatological Data in 1950. In its early years, the database only collected data on tornadoes and their impacts. Information on thunderstorms and their impact was added after 1955. The name Storm Data was officially used later in 1959 when data of all severe weather events were added into the database. Emergency management officials, media, insurance companies, and law enforcement are the main sources of data included in Storm Data [31]. The database includes different classes of circumstances/location of the deaths or injuries (mostly at a county level), defines the timing of the event by the segment of the day (morning, afternoon, night, etc.), age and gender of victims, and for vehicle-related fatalities, the database includes information about the road type in some cases.

For this study, the data of vehicle-related flood fatalities, which was attributed to coastal floods, flash floods, floods, heavy rain, and tropical storms, was collected from the Storm Data website for Texas for 1959 to 2019. Fatality data before 1996 was available only as PDF files. In total, 444 Storm Data reports in PDF format were reviewed (1959-1995). Rainfall data was obtained from the National Centers for Environmental Information (NCEI) of the National oceanic and Atmospheric Administration [32]. Texas flood fatality data was downloaded for each year and then combined. In-house R scripts were developed to extract data needed for the analysis. R scripts were used to run Mann-Kendall nonparametric trend analysis. Excel was used to perform analysis of variance (ANOVA) to compare variables such as gender. $R$ scripts were used to process rainfall data and compare rain and fatality data.

\section{Results}

\subsection{Temporal Analysis}

In total, 6478 flood fatalities happened in the past 61-year study period in the contiguous United States. Approximately $60 \%$ of the fatalities were recorded with circumstance details in Storm Data. Furthermore, $58 \%$ of the fatalities with known circumstance details were vehicle-related. Compared to the other states, Texas has the highest number of flood fatalities (1069), with an annual average of 17.52 fatalities, from 1959 to 2019. Those fatalities resulted from 576 flood events, as shown in Table 1 . However, all events, except five, resulted in a single vehicle-related flood fatality. A family of six died in a vehicle in Houston during Hurricane Harvey. The vast majority, 86.6\%, of all flood events caused less than four deaths per event. During the study period, there were 570 vehicle-related flood fatalities, with an annual average of 9.34 fatalities. There is no significant trend for the vehicle-related flood fatalities over the 61 years based on the Mann-Kendall non-parametric test. Overall, $53 \%$ of the total flood fatalities were vehicle-related in Texas. The annual variability of vehicle-related flood fatality was similar to that of the flood fatalities. The most devastating event during the study period, Harvey, a Category 4 hurricane which went ashore on Texas on 26 August 2017, led to 67 flood fatalities. 
Twenty of these 67 deaths were vehicle-related. The most vehicle-related flood fatalities, 33, occurred in 2007 in Texas and the second (28) and the third (27) in 1979 and 1966, respectively. On 5 May 1995, 16 people died due to a flash flood and 10 of them were vehicle-related. Flash floods caused 26 deaths and 23 of them were related to a vehicle on 17 October 1998.

Table 1. Death per flood event in Texas, 1959-2019.

\begin{tabular}{ccc}
\hline $\begin{array}{c}\text { Death Per } \\
\text { Event }\end{array}$ & Event Number & Proportion (\%) \\
\hline 1 & 355 & 61.6 \\
2 & 96 & 16.7 \\
3 & 48 & 8.3 \\
4 & 13 & 2.3 \\
5 & 10 & 1.7 \\
$6-10$ & 14 & 2.4 \\
$11-20$ & 6 & 1.0 \\
$>20$ & 3 & 0.5 \\
Events total & 576 & \\
Death total & 1069 & \\
\hline
\end{tabular}

Total flood fatalities and vehicle-related fatalities occurred in every year of the study period, except 2011 when Texas witnessed a major drought. The highest number of flood fatalities, 70, occurred in 2017, while the highest number of vehicle-related fatalities, 32, occurred in 2007 (Figure 2). Annual fluctuations were high for both total flood fatalities and vehicle-related flood fatalities. Both total and vehicle-related flood fatalities are significantly correlated with rainfall in Texas on the annual time scale, with Pearson correlation coefficients of 0.50 and 0.53 , respectively. To illustrate the flood fatality risk, total flood fatalities and vehicle-related flood fatalities have been normalized by the corresponding annual Texas population (Figure 3). The figure shows statistically significant decreasing trends for both normalized rates, with the total number of flood fatalities showing a higher decreasing rate with $p$-values of 0.01 and 0.03 , respectively, based on the Mann-Kendall nonparametric trend test. The high fluctuation of the annual proportion of vehicle-related flood fatalities (using total fatalities as a reference), which ranges between $10 \%$ and $100 \%$, is shown in Figure 4, which shows a small increasing trend that is not statically significant. As expected, there is no correlation between the proportion of vehicle-related flood fatalities and annual rainfall (Pearson correlation coefficient of 0.0).

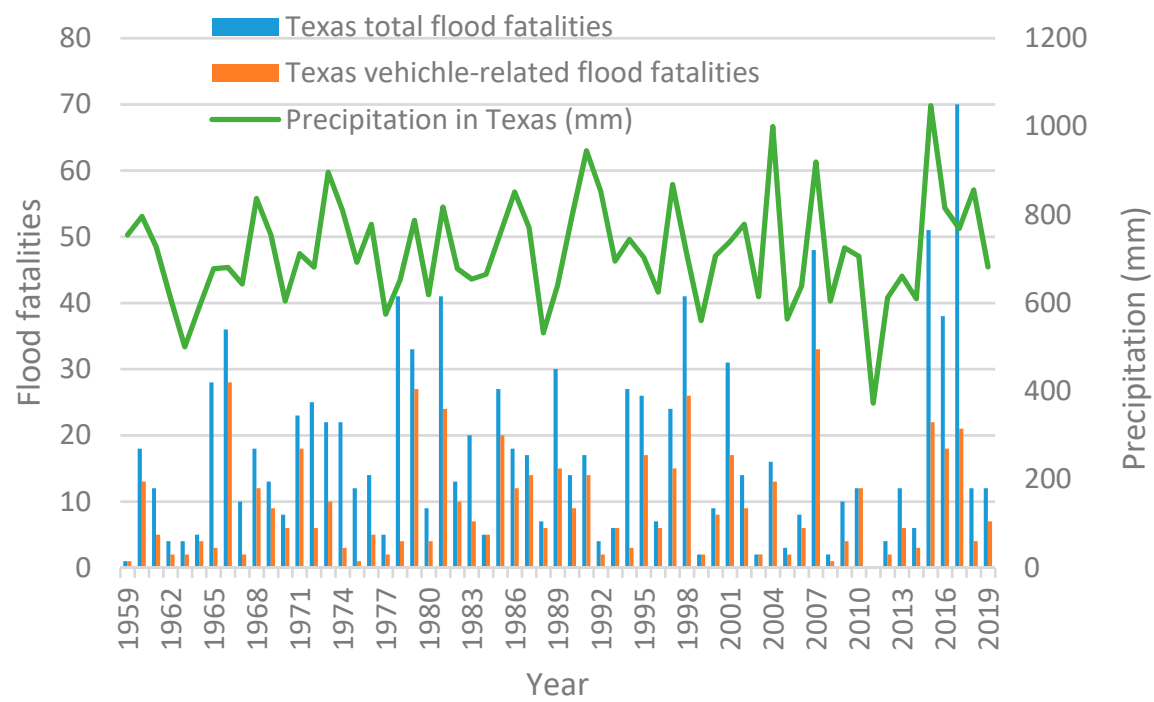

Figure 2. Numbers of annual flood fatalities and vehicle-related flood fatalities in Texas, 1959-2019. 


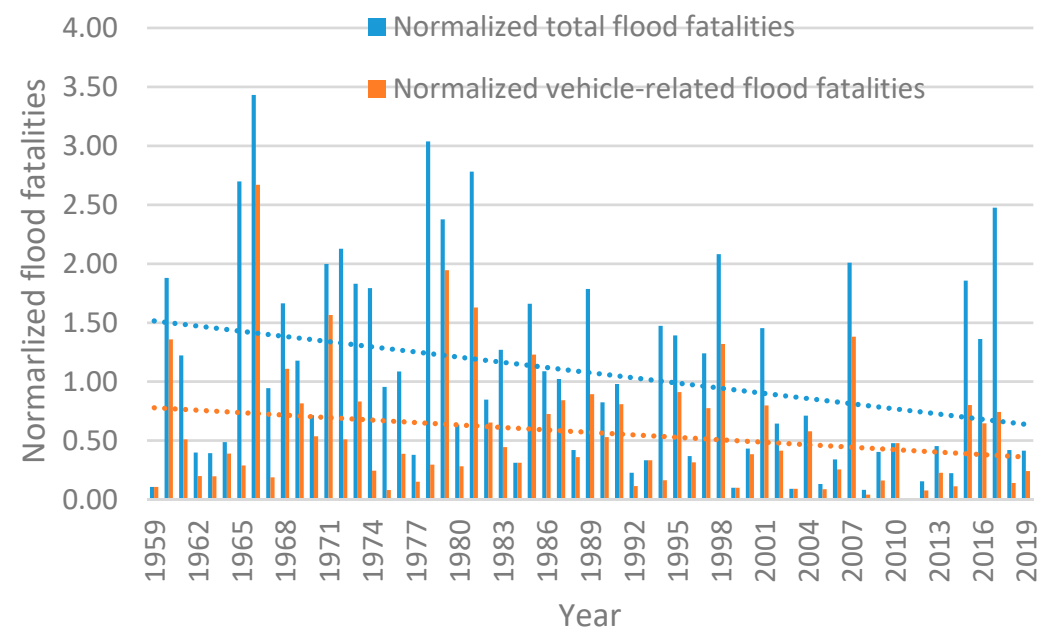

Figure 3. Normalized numbers of total flood fatalities and vehicle-related flood fatalities per 1 million people in Texas, 1959-2019.

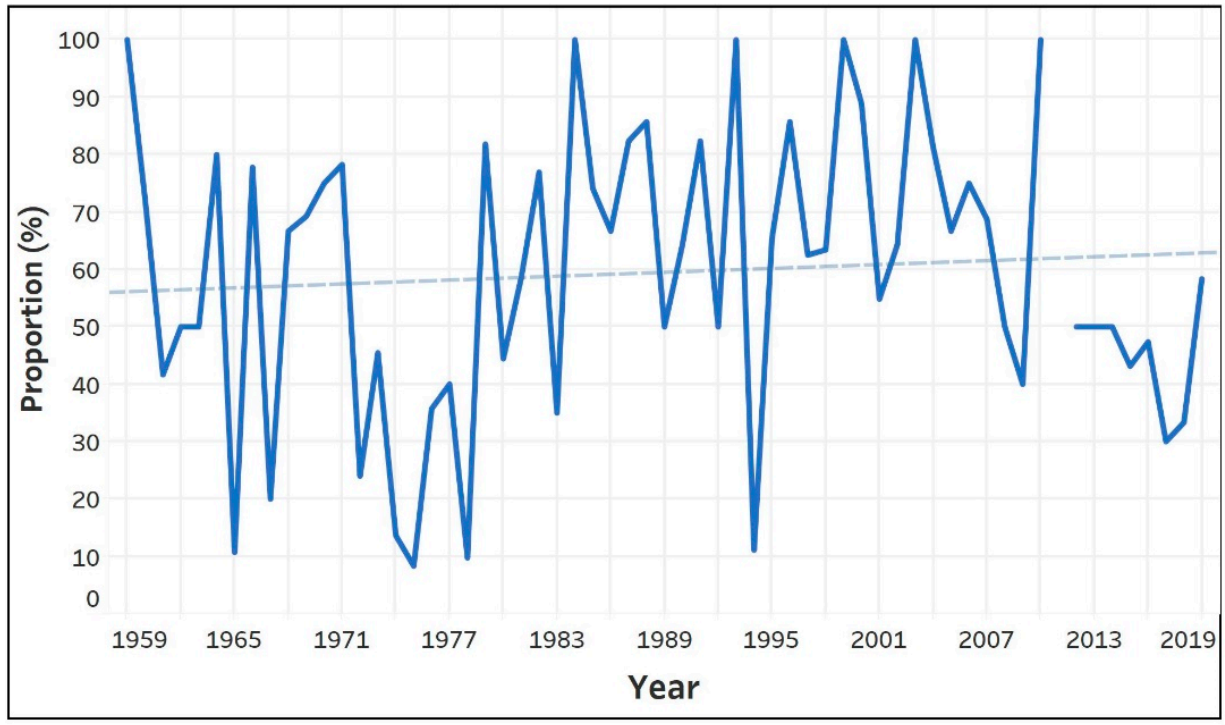

Figure 4. Annual proportion of vehicle-related flood fatalities for all flood fatalities in Texas, 1959-2019 (no flood fatalities occurred in 2011).

The proportions of vehicle-related flood deaths estimated in this study reflect the variations in the proportions reported in some previous studies. Different study areas and study periods were responsible for this discrepancy. For example, Ashley and Ashley [16] found that $63 \%$ of flood fatalities that were recorded with occurrence details were vehicle-related in the contiguous United States from 1959 to 2005 , while Sharif et al. [28] reported that $76 \%$ of flood deaths were vehicle-related when they studied all flood fatalities in Texas from 1959 to 2008. In agreement with this study, Kellar and Schmidlin [23] found that more than $50 \%$ of flood deaths caused by flash flood in the US from 1995 to 2005 were related to vehicles.

\subsection{Monthly Distribution of Fatalities}

As seen in Figure 5, May (129), October (89), and April (77) witness the highest numbers of vehicle-related flood fatalities. Kellar and Schmidlin [23] found January (74), September (68), and May (65) to be the top three months in terms of vehicle-related fatalities from 1995 to 2005 in the United States. Sharif et al. [28] reported that May, June, and October were the top three months with the most flood fatalities in Texas from 1959 to 2008. The vehicle-related fatality monthly pattern agrees with that 
of the monthly precipitation in Texas and more so with that in the Flash Flood Alley, as seen in Figure 5, especially the peaks of May and October. Very few vehicle-related fatalities occur in the driest months, which are February and January.

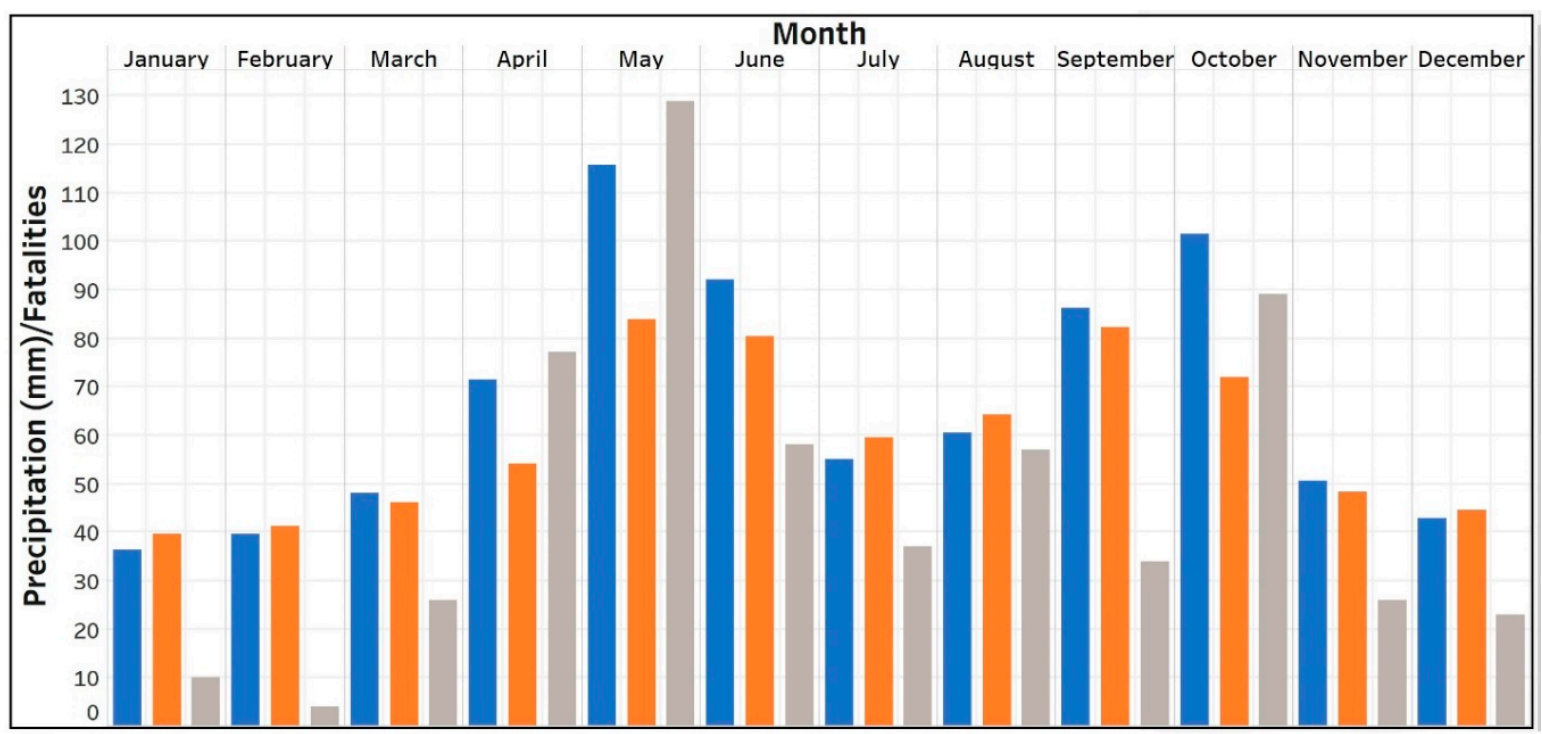

Monthly precipitation in flash flood alley

- Monthly precipitation in texas

Vehicle related flood fatality

Figure 5. Monthly distribution of vehicle-related flood fatalities and average monthly precipitation in Flash Flood Alley and average monthly precipitation in Texas, 1959-2019.

\subsection{Time of the Day}

Among all the 570 vehicle-related flood fatalities during the study period, $416(73 \%)$ were recorded with the time of the day they occurred. The timing of some storm/flooding events was described by the starting and ending hours. However, there is not enough detail regarding the storm movement and exact time of fatality. The time of occurrence is described as morning, noon, afternoon, evening, and night, without a specific description of the hour. Most likely these time periods correspond to 5:00 am-before noon (morning), around 12:00 pm (noon), noon to 5:00 pm (afternoon), 5:00 to 9:00 pm (evening), and 9:00 pm to 5:00 am (night). A large number of these vehicle-related flood fatalities with temporal details recorded (more than $45 \%$ ) occurred at night (Figure 6 ) and 31\% occurred in the morning, including the dark early morning hours. Sharif et al. [28] found that a higher percentage (52\%) of flood fatalities, with occurrence circumstances recorded, happened at night in Texas. The percentages are significantly lower for the afternoon and evening periods. Ahmed et al. [33] found that the total percentage of vehicle-related flood fatalities that occurred in both the evening and at night accounted for $50 \%$ of those with known time details, while the morning hours accounted for only $8 \%$. 


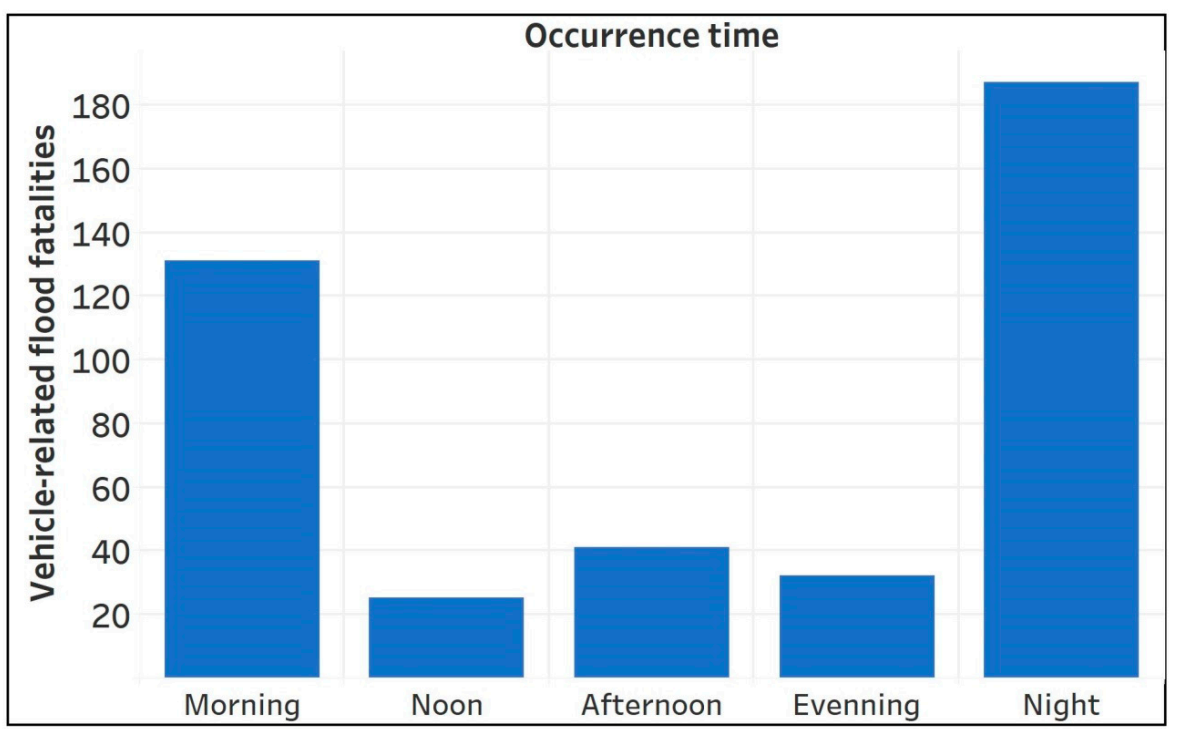

Figure 6. Numbers of vehicle related flood fatalities in Texas, 1959-2019 by occurrence time.

\subsection{Demographics of the Victims}

Gender information was reported for $483(85 \%)$ of the vehicle-related flood fatalities in Storm Data. Males are almost twice as likely to die in vehicle-related flood accidents than females (63\% to 37\%), as seen in Figure 7. ANOVA test results showed that there was a difference between males and female, with $p$-values of less than 0.01 . Although high, this male overrepresentation is lower than the $70 \%$ value reported by Jonkman and kelman [10] and the 85\% reported by Coates [24]. In Texas, Sharif et al. [28] reported that male flood fatalities accounted for $68.4 \%$ of all fatalities. Kellar and Schmidlin [23] found that $60 \%$ of all vehicle-related flood deaths that were recorded with gender information were male victims. Ahmed et al. (2018) reported that $66 \%$ of all the vehicle-related flood deaths were males [27]. They found that when the role of the victims in the vehicle was specified as driver or passenger, male victims accounted for $72 \%$ of all the driver victims and $57 \%$ of all the passenger victims [33]. Diakakis' [34] study reported a male-female ratio of 3.6 to 1 . Unfortunately, Storm Data does not specify the driver in the vast majority of the incidents, but males are always more likely to be involved in risky behavior than females (e.g., [35]). Moreover, the presence of females in the vehicle, whether as a driver or passenger, was correlated with significantly lower accident risk [36]. Chen et al. [37] demonstrated that the presence of a male as a driver or passenger in a vehicle almost doubles the likelihood/severity of an accident.

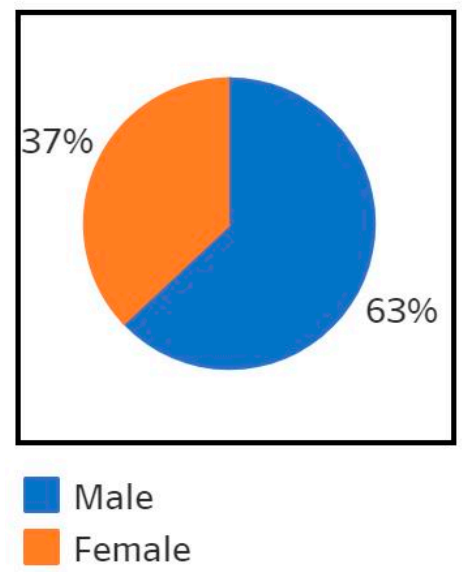

Figure 7. Proportions of vehicle-related flood fatalities by gender. 
Storm Data provided information on the ages of individuals involved in $382(67 \%)$ of the vehicle-related flood fatalities. The age group of 20-29 years covers the most vehicle-related flood fatalities for both male victims (42) and female (25), as seen in Figure 8. The age group of 80 and above is the group that has the lowest male (14) and female fatalities (8). Male victims are significantly more involved than females among all the age groups, except the 10-19 age group. For the age group of 40-49 and 70-79, the numbers of male victims are more than twice that of females. In general, victims of flood incidents characterized by active behaviors were, on average, younger by a significant margin than the ones that perish exhibiting a passive behavior [34].

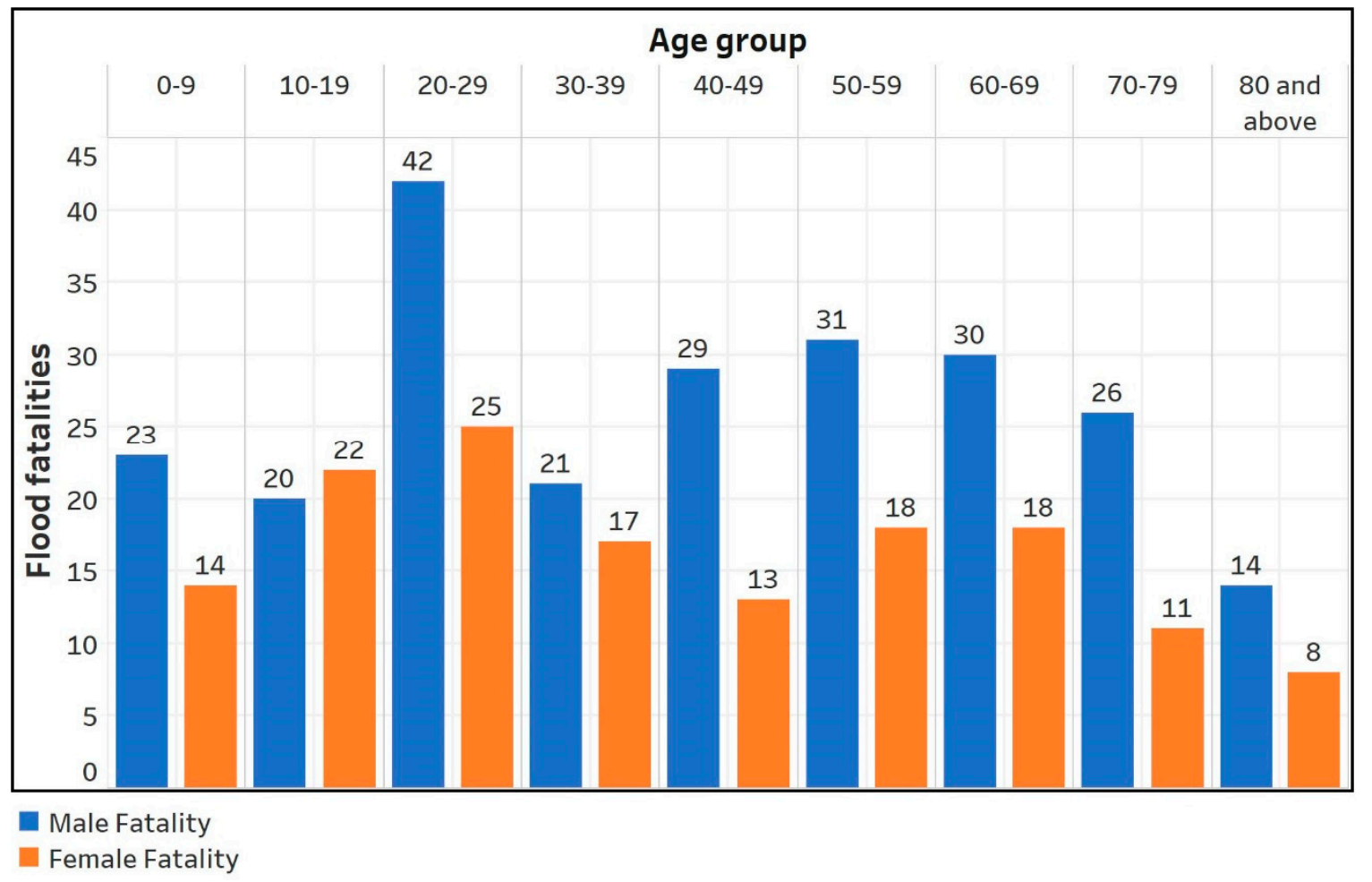

Figure 8. Numbers of vehicle-related flood fatalities in Texas, 1959-2019 by age and gender.

\subsection{Flood Types}

Flash floods were the dominant flood type that caused fatalities. They were responsible for 347 (61\%) of all vehicle-related flood fatalities (Table 2). This is $20 \%$ higher compared to the findings of Sharif et al. [28], who showed that about $50 \%$ of all flood fatalities were caused by flash flooding in Texas from 1959 to 2008. However, Zevin [17] reported that 80-90\% of annual flood fatalities were caused by flash flooding without specifying the location or time. Ashley and Ashley [16] found that flash floods were the main flood type that caused most flood fatalities. Kellar and Schmidlin [23] also found that flash flooding caused the most vehicle-related fatalities. Among other types included in Storm Data, floods (excluding flash floods) caused the second highest number of vehicle-related flood fatalities, 107, followed by heavy rain, 51 . The other flood types accounted for $11 \%$ of the fatalities combined. It is not clear what is meant by "flood" in Storm Data. Most probably, this refers to a river flood or a flood that NWS has not classified as a flash flood. 
Table 2. Vehicle-related flood fatalities by flood types in Texas, 1959-2019.

\begin{tabular}{ccc}
\hline Flood Types & Vehicle-Related Flood Fatalities & Proportion (\%) \\
\hline Heavy Rain & 51 & 9 \\
Heavy Rain \& Flooding & 23 & 4 \\
Heavy Rain and Flash Flooding & 16 & 3 \\
Flood & 107 & 19 \\
Flash Flooding & 347 & 61 \\
Flash Flood and Flood & 8 & 1 \\
Flash Flooding and River Flooding & 3 & 1 \\
Flooding due to Hurricane/Tropical & 11 & 2 \\
Storm/Tornadoes/Cyclones & 4 & 1 \\
Tidal/Coastal Flooding & & \\
\hline
\end{tabular}

\subsection{Fatality Locations}

Information on the locations where vehicle-related flood deaths occurred was reported in Storm Data. These fatality locations have been classified into 10 categories (Table 3). The details on the exact locations were obtained from the part "Event Narrative" in Storm Data, which describes the fatal incidents when "driving on a flooded bridge", "driving on a flooded highway", "crossing river", "crossing creek", "driving over a culvert", "inside vehicle", or other places. The uses of these categories are not precise and not consistent among events and it seems that they are not mutually exclusive. Moreover, location details were reported for only 234 (41\%) of the vehicle-related flood fatalities. About $30.8 \%$ of the vehicle-related fatalities occurred on a road and $23.5 \%$ occurred when driving through a flooded creek. "Event Narrative" mentioned that $13.2 \%$ died inside their vehicles, which may include those who died inside their vehicles that were swept away from roads or creeks. Storm Data specifically mentions occurrence at low-water crossings for only $8.5 \%$ of the vehicle-related fatalities. However, the authors suspect that almost all of the fatalities that occurred on creeks, according to "Event Narrative", and most of those that occurred on the road, or described as "in vehicle" or "other", actually occurred at low-water crossings where a road meets a creek. Thus, we suspect that over $80 \%$ of the fatalities occurred at low-water crossings where floodwater moves deep and fast enough to sweep away a vehicle. About $50 \%$ of the vehicle-related flood deaths described in the study by Kellar and Schmidlin [23] occurred where the road crosses a water course (in the presence or absence of a bridge). Ahmed et al. (2018) reported similar numbers [33].

Table 3. Vehicle-related flood fatalities by roadway types in Texas, 1959-2019.

\begin{tabular}{ccc}
\hline Roadway Types & Vehicle-Related Flood Fatalities & Proportion (\%) \\
\hline Bridge & 14 & 6.0 \\
Highway & 15 & 6.4 \\
River & 7 & 3.0 \\
Creek & 55 & 23.5 \\
Culvert & 1 & 0.4 \\
On the road & 72 & 30.8 \\
Inside vehicle & 31 & 13.2 \\
Water crossing & 20 & 8.5 \\
Other (farm, drainage, ditch, lake, & 19 & 8.1 \\
underpass, arroyo, pond, barricade) & &
\end{tabular}

\subsection{Spatial Analysis}

Figure 9 shows the spatial distribution of vehicle-related flood fatalities at the county level. Only nine of the vehicle-related fatalities did not have the county identified, e.g., Storm Data reports that the event caused a vehicle related fatality in south Texas. The 561 vehicle-related flood fatalities were distributed over 113 out of the 254 counties in Texas. Only nine counties had more than 10 vehicle-related 
flood fatalities over the 61-year study period. The top counties in reporting vehicle-related floods are Bexar (54), Dallas (44), Travis (37), Harris (35), and Tarrant (33). These are highly urbanized counties, including the major cities of San Antonio, Dallas, Austin, Houston, and Fort Worth, respectively. Except for Harris, all of these counties are located in Flash Flood Alley (Figure 1). Figure 9 clearly shows that the vehicle-related fatalities are concentrated in Flash Flood Alley. Counties in the Flash Flood Alley account for about $83 \%$ of the vehicle-related flood fatalities in Texas. The rapid change of geographic elevation along the edge of Balcones Escarpment and the thin soils enhance the land surface response to storms that stall in this area, creating perfect conditions for very fast flowing water during or immediately after rainfall. The continued urbanization and explosive population growth increase the flood risk in the counties in Flash Flood Alley [28,38]. Almost all the counties with more than 10 deaths were clustered on the edge of Balcones Escarpment, except for Harris County (35) and Gregg County (11). Harris County, located close to the Gulf of Mexico, witnessed major flooding events in 2015 (Memorial Day Flood), 2016 (Tax Day Flood), 2017 (Hurricane Harvey), and 2019 (Tropical Storm Imelda) that led to several fatalities. For instance, in 2017, Hurricane Harvey caused 13 vehicle-related flood deaths in Harris County [39]. The effect of exposure can be seen in Figure 10, where the fatalities are normalized by population. Even in the Flash Flood Alley, the densely populated counties (around the cities of San Antonio, Austin, and Dallas, Figure 1) show modest fatality rates. The same applies to Harris County. Rural counties in and near the Alley have the highest rates. The proportion of vehicle-related flood fatalities (of the total flood fatalities) is generally higher in the Flash Flood Alley, as seen in Figure 11. Some of the counties outside the Alley, with low numbers of flood facilities, in general, also show high proportions of vehicle related fatalities.

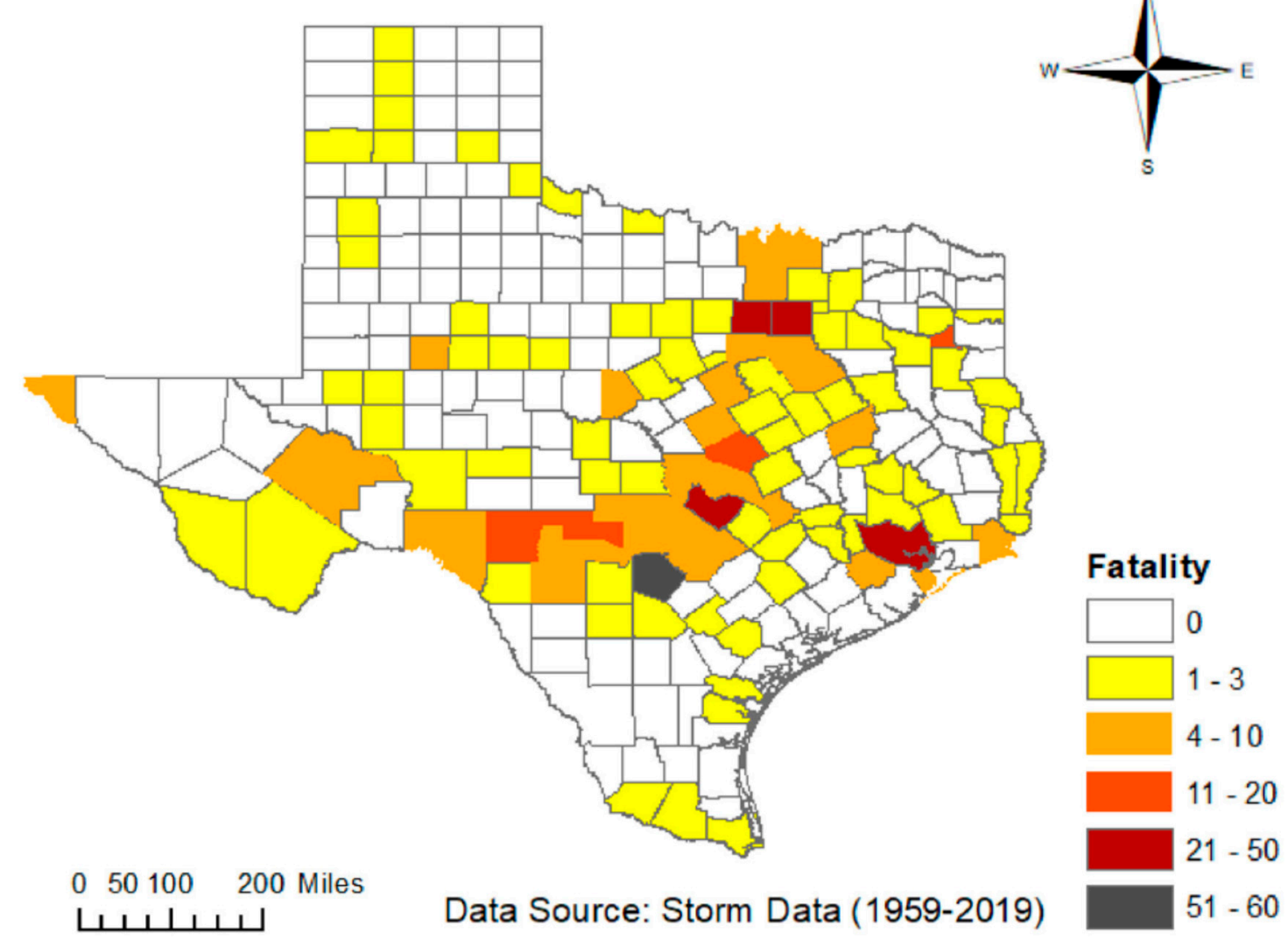

Figure 9. Vehicle-related flood fatalities by county in Texas, 1959-2019. 


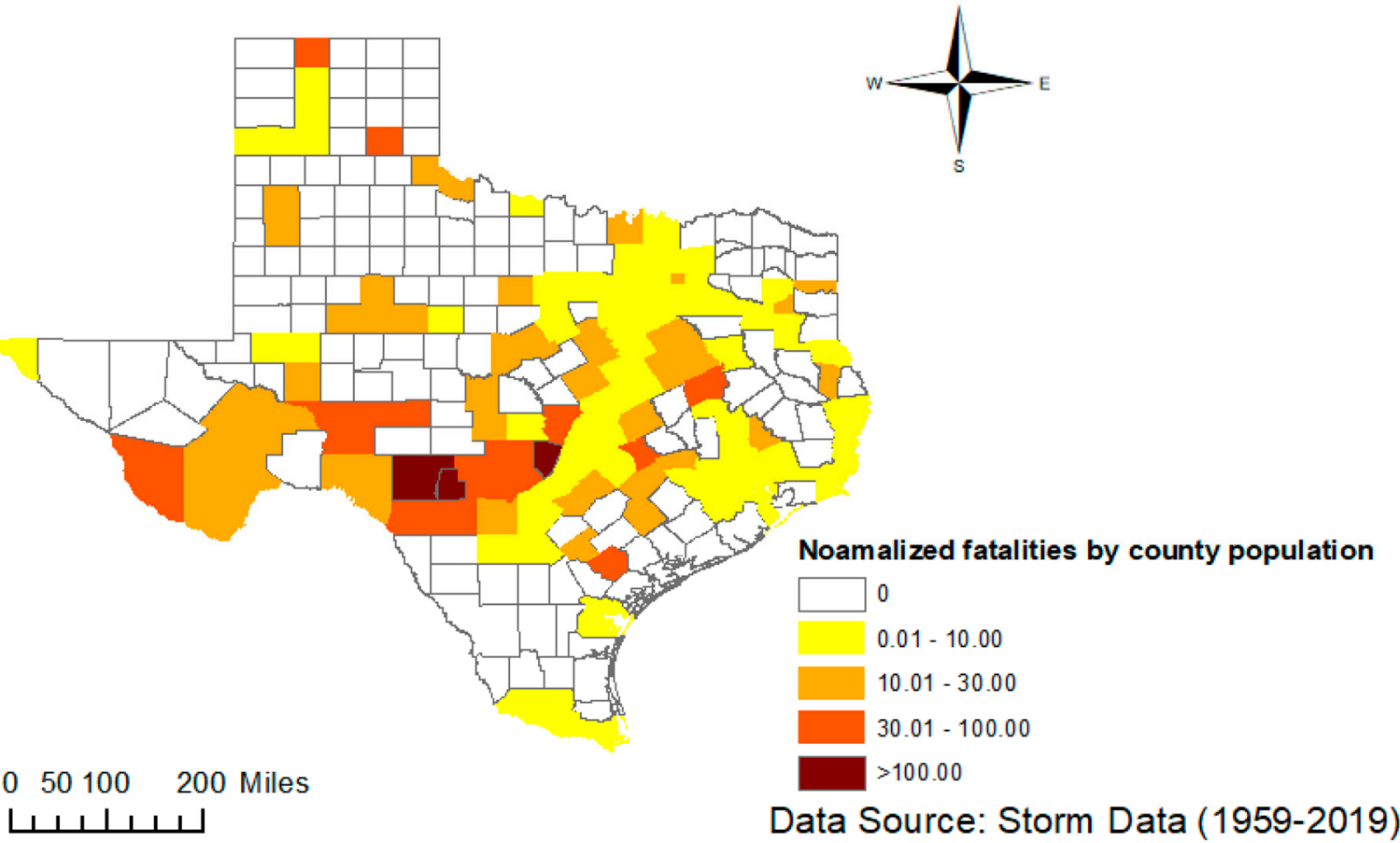

Figure 10. Normalized vehicle-related flood fatalities by county in Texas (per 100,000 residents), 1959-2019.

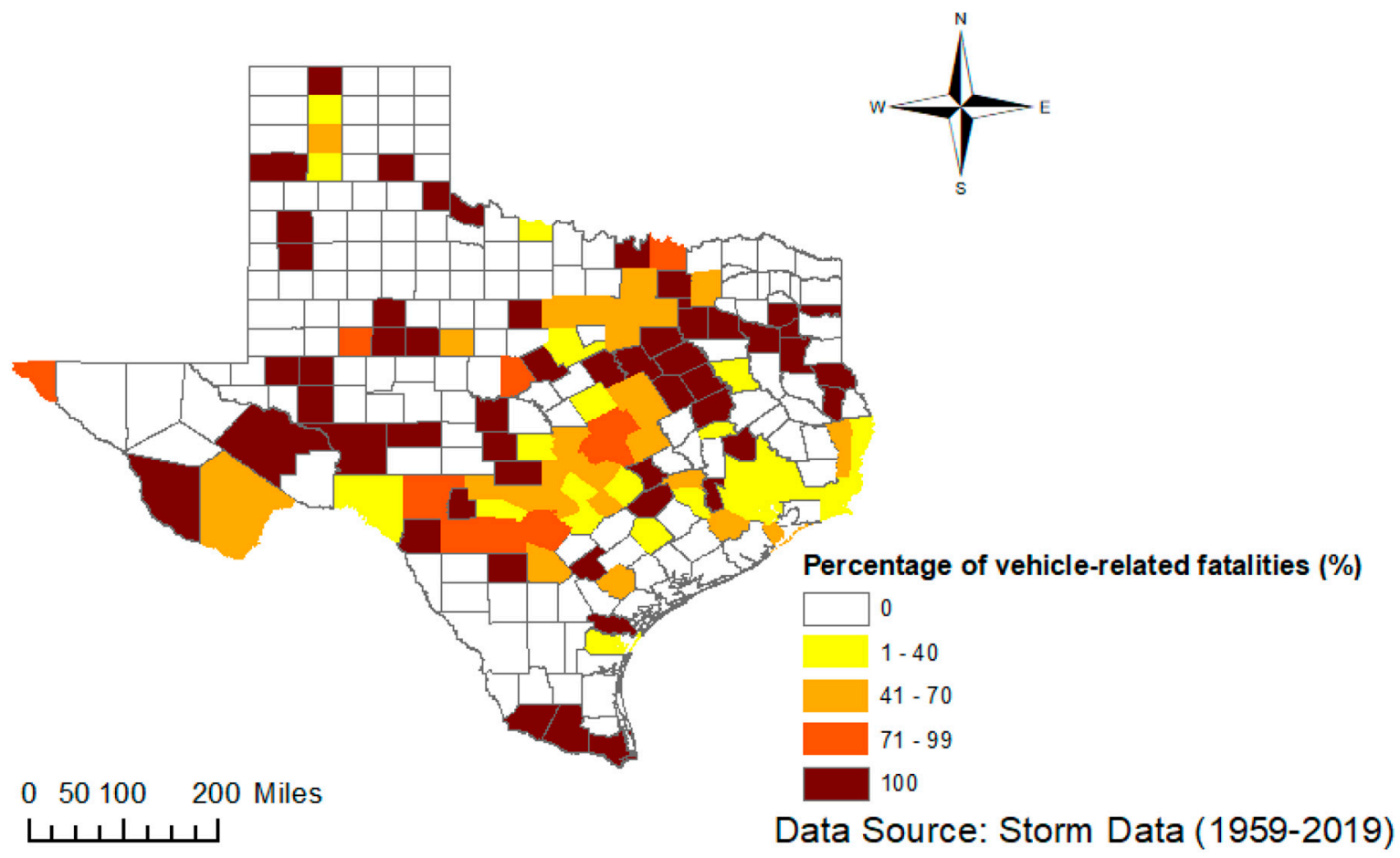

Figure 11. The proportion of vehicle-related flood fatalities in total flood fatalities by county in Texas, 1959-2019.

\section{Discussion and Conclusions}

In this study, the data of vehicle-related flood fatalities in Texas from 1959 to 2019 has been examined in detail. Temporal and spatial patterns of vehicle-related flood fatalities, the circumstances when vehicle-related flood death occurrs, the demographic characteristics of victims, the type of floods leading to fatalities, and roadway types where vehicle-related flood deaths occurred were included in the analysis. A total of 570 vehicle-related flood deaths occurred in Texas during the 61-year study 
period. All but three events resulted in a single fatality. These fatalities represent $58 \%$ of the total flood fatalities. Providing the details of vehicle-related flood deaths can help officials and the public to better understand flood hazards. Furthermore, policy makers and engineers can have a better estimation of the flood impacts and take corresponding proactive mitigation measures. Resources can be invested strategically to improve the effectiveness of education programs by specifically targeting vulnerable groups. Financial resources can be directed to emergency preparedness hazard communication and address immobility issues.

The annual distribution of these fatalities was similar to that of the general flood fatalities. Both types of fatalities show statistically significant decreasing trends, indicating that population growth in Texas far outpaces the number of flood fatalities, helping to decrease the normalized fatality rates. The downtrend in normalized fatalities may be partially attributed to improvement in official flood warning systems or emergency responses. Also, community awareness efforts such as the "Turn Around Don't Drown" campaign and the repeated exposure of Texans to major flood events may have modified their flood risk perceptions or improved their risk awareness, leading to more conscious decisions during flooding. Monthly distribution of vehicle-related fatalities follows that of rainfall in the Flash Flood Alley, similar to that of all flood fatalities reported by Sharif et al. [22]. Flash flood caused $61 \%$ of all vehicle-related flood fatalities and most of them (more than $80 \%$ ) occurred in the Flash Flood Alley region. The high risk in this region can be reduced by investment in roadway flood safety improvement, including early warnings, better road flooding signage, indicating alternate routes during flooding, and preemptive transportation protocols. Topography, weather, and land surface characters combine to initiate flash floods, which catch people off-guard due to their rapid development $[16,28]$. Night accounted for $45 \%$ of the total vehicle-related deaths among all the times of day. Mooney [14] found that nearly 75\% of flash flood deaths occurred during darkness hours with low visibility.

Males made up a greater percentage of flood victims than females, $62 \%$ to $38 \%$. This result agrees with previous studies suggesting that males were more likely to take risks during a flood event $[10,21,23,35,40]$. The most vehicle-related flood deaths occurred in the age group of 20-29 years for both male and female victims; possibly, because people in this age group underestimate the hazard of floodwaters and overestimate their driving skills and the protective capability provided by their vehicles. Education programs should be tailored to male drivers in this age group. Old drivers are less likely to drive in inclement conditions [41], which is supported by the results of this study. It is clear that social psychological factors (e.g., attitudes and social norms) should guide efforts aimed at improving individuals' behavioral decisions during flood situations [42]. Gender-specific educational programs may also be of help [10]. Evidence from Australia showed the effectiveness of such approaches [10].

Individual behavior also plays an important role in affecting vehicle-related flood fatalities. It seems that many people underestimate the destructive power of floodwaters and overestimate their driving skills and the protective capability of their vehicles. Rescuing personal properties, rescuing people without professional training, working for emergency and support services, and driving to a specific destination were among the reasons people drive into floodwaters intentionally. Drivers in fatal crashes frequently failed to follow the warning signs and indicators. Drobot et al. [15], using data from survey questionnaires conducted in Denver and Austin, found that people who do not take flood warning signs seriously, who did not experience floods previously, and who are not aware that the area they live in is flood-prone are more likely to drive into floodwaters. Hamilton et al. [14] found that experience, individual perceptions, and social and environmental context were the main factors that influenced people in making the decision to drive through floodwaters. Since it is not easy to assess the severity of flood conditions as they evolve, motorists seek additional sources of information and weigh the dangers against other situational factors on a case-by-case basis, such as their prior successful crossing of other vehicles, road signage and barricades, presence of passengers, and their perceived risk of personal injury or damage to their vehicle [43]. All these factors should be included in educational programs. 
It is important to address the misconception that vehicles, especially light trucks and SUVs, can safely cross flood roads and creeks. The Federal Emergency Management Agency [44] reported that six inches of floodwater can reach the bottom of most passenger vehicles and then drivers will lose control of their car, either due to the engine stalling or the force of the flowing water. Two feet of rushing water can lift and float most cars, including sport utility vehicles and pick-ups in a short time. Moreover, often vehicle occupants had little time to escape when vehicles were trapped and submerged in floodwater in most situations. This misconception has been discussed by some other researchers in some other regions $[20,21]$. Similar research can be conducted in Texas in the future to estimate the water depth and velocity condition for some of the cases of vehicle fatalities, especially in the Flash Flood Alley. Results of such studies can be included in driver license manuals and defensive driving classes. Additionally, transportation agencies and insurance companies can alert the public about the flood hazards with the recorded cases of vehicle-related flood fatalities without releasing personal information. Auto manufacturers can participate in the education program to introduce vehicle performance in different weather conditions.

It is clear that Storm Data is not a completely perfect source for the details of vehicle-related flood fatalities, mainly due to the inconsistency of the details recorded. This may be because the information is collected from different sources, including the media. For example, details of location, demographics, and time are missing for many incidents. Moreover, there are some conflicts in the descriptions of the flood type fatalities with fatalities resulting from tropical storms being attributed randomly to the storm or the ensuing flooding. When the roads cross a creek, the location is specified as only either a creek or a road. However, Storm Data is the most comprehensive and primary source for vehicle-related flood fatality data $[3,16,18]$. Similarly, Ahmed et al. (2020) found that data from the Australian National Coronial Information System (NCIS) suffered from inconsistencies and missing details [21]. The authors hope that the NWS can use the feedback from this and previous studies in Storm Data to improve the quality of the information in this invaluable source.

Author Contributions: H.O.S. guided this research, contributed significantly to preparing the manuscript for publication, and developed the research methodology. Z.H. processed the data and conducted the analysis. Z.H. prepared the first draft. H.O.S. performed the final overall proofreading of the manuscript. All authors have read and agreed to the published version of the manuscript.

Funding: The first author was funded through a scholarship from the Chinese Scholarship Council (No. 201606300024).

Conflicts of Interest: The authors declare no conflict of interest.

\section{References}

1. Guha-Sapir, D. EM-DAT: The Emergency Events Database; Université catholique de Louvain (UCL): Brussels, Belgium, 2020; Available online: www.emdat.be (accessed on 19 February 2020).

2. French, J.; Ing, R.; von Allmen, S.; Wood, R. Mortality from flash floods: A review of national weather service reports, 1969-81. Public Health Rep. 1983, 98, 584-588. [PubMed]

3. Dittmann, R.H. Annual Flood Death Statistics per State per Capita for the United States and Puerto Rico during the Period 1959-1991; National Oceanic and Atmospheric Administration: Washington, DC, USA, 1994.

4. Munich, R.N. Natural Catastrophe Know-How for Risk Management and Research; Natural Catastrophe Online Tool. 2019. Available online: http://natcatservice.munichre.com/ (accessed on 19 February 2020).

5. Chowdhury, A.M.R.; Bhuyia, A.U.; Choudhury, A.Y.; Sen, R. The Bangladesh Cyclone of 1991: Why So Many People Died. Disasters 1993, 17, 291-304. [CrossRef] [PubMed]

6. Gerritsen, H. What happened in 1953? The Big Flood in the Netherlands in retrospect. Philos. Trans. R. Soc. A 2005, 363, 1271-1291. [CrossRef] [PubMed]

7. Borden, K.A.; Cutter, S.L. Spatial patterns of natural hazards mortality in the United States. Int. J. Health Geogr. 2008, 7, 64. [CrossRef] [PubMed]

8. Hahn, D.J.; Viaud, E.; Corotis, R.B. Multihazard Mapping of the United States. ASCE ASME J. Risk Uncertain. Eng. Syst. Part A 2017, 3, 04016016. [CrossRef] 
9. National Weather Service. Flash Flooding Definition. Available online: https://www.weather.gov/phi/ FlashFloodingDefinition (accessed on 25 October 2019).

10. Jonkman, S.N.; Kelman, I. An Analysis of the Causes and Circumstances of Flood Disaster Deaths. Disasters 2005, 29, 75-97. [CrossRef]

11. Terti, G.; Ruin, I.; Anquetin, S.; Gourley, J.J. A Situation-Based Analysis of Flash Flood Fatalities in the United States. Bull. Am. Meteorol. Soc. 2017, 98, 333-345. [CrossRef]

12. Petrucci, O.; Papagiannaki, K.; Aceto, L.; Boissier, L.; Kotroni, V.; Grimalt, M.; Llasat-Botija, M.; Rossello, J.; Vinet, F.; Llasat, M.C.; et al. MEFF: The database of Mediterranean Flood Fatalities (1980 to 2015). J. Flood Risk Manag. 2018, 12, e12461. [CrossRef]

13. Diakakis, M.; Deligiannakis, G. Flood fatalities in Greece: 1970-2010. J. Flood Risk Manag. 2017, 10, 115-123. [CrossRef]

14. Hamilton, K.; Peden, A.E.; Keech, J.J.; Hagger, M.S. Driving through floodwater: Exploring driver decisions through the lived experience. Int. J. Disaster Risk Reduct. 2019, 34, 346-355. [CrossRef]

15. Drobot, S.; Benight, C.; Gruntfest, E. Risk factors for driving into flooded roads. Environ. Hazards 2007, 7, 227-234. [CrossRef]

16. Ashley, S.T.; Ashley, W.S. Flood Fatalities in the United States. J. Appl. Meteorol. Clim. 2008, 47, 805-818. [CrossRef]

17. Zevin, S.F. Steps toward an Integrated Approach to Hydrometeorological Forecasting Services. Bull. Am. Meteorol. Soc. 1994, 75, 1267-1276. [CrossRef]

18. Mooney, L.E. Applications and Implications of Fatality Statistics to the Flash Flood Problem. In Proceedings of the Fifth Conference on Hydrometeorology, Tulsa, OK, USA, 17-19 October 1983; pp. 127-129.

19. Doocy, S.; Daniels, A.; Murray, S.; Kirsch, T.D. The Human Impact of Floods: A Historical Review of Events 1980-2009 and Systematic Literature Review. PLoS Curr. 2013, 5. [CrossRef] [PubMed]

20. Špitalar, M.; Gourley, J.J.; Lutoff, C.; Kirstetter, P.E.; Brilly, M.; Carr, N. Analysis of flash flood parameters and human impacts in the US from 2006 to 2012. J. Hydrol. 2014, 519, 863-870. [CrossRef]

21. Ahmed, M.A.; Haynes, K.; Taylor, M. Vehicle-related flood fatalities in Australia, 2001-2017. J. Flood Risk Manag. 2020, 13, e12616. [CrossRef]

22. Jonkman, S.; Vrijling, J. Loss of life due to floods. J. Flood Risk Manag. 2008, 1, 43-56. [CrossRef]

23. Kellar, D.; Schmidlin, T. Vehicle-related flood deaths in the United States, 1995-2005. J. Flood Risk Manag. 2012, 5, 153-163. [CrossRef]

24. Coates, L. Flood Fatalities in Australia, 1788-1996. Aust. Geogr. 1999, 30, 391-408. [CrossRef]

25. Špitalar, M.; Brilly, M.; Kos, D.; Žiberna, A. Analysis of Flood Fatalities-Slovenian Illustration. Water 2019, 12, 64. [CrossRef]

26. Xia, J.; Teo, F.; Lin, B.; Falconer, R.A. Formula of incipient velocity for flooded vehicles. Nat. Hazards 2010, 58, 1-14. [CrossRef]

27. Jonkman, S.; Penning-Rowsell, E. Human Instability in Flood Flows1. JAWRA J. Am. Water Resour. Assoc. 2008, 44, 1208-1218. [CrossRef]

28. Sharif, H.O.; Jackson, T.L.; Hossain, M.; Zane, D. Analysis of Flood Fatalities in Texas. Nat. Hazards Rev. 2015, 16, 04014016. [CrossRef]

29. Furl, C.; Sharif, H.; Zeitler, J.W.; El Hassan, A.; Joseph, J. Hydrometeorology of the catastrophic Blanco river flood in South Texas, May 2015. J. Hydrol. Reg. Stud. 2018, 15, 90-104. [CrossRef]

30. Furl, C.; Ghebreyesus, D.; Sharif, H.O. Assessment of the Performance of Satellite-Based Precipitation Products for Flood Events across Diverse Spatial Scales Using GSSHA Modeling System. Geosciences 2018, 8, 191. [CrossRef]

31. National Centers for Environmental Information. Storm Events Database; FAQ. 2007. Available online: https://www.ncdc.noaa.gov/stormevents/faq.jsp (accessed on 4 February 2020).

32. National Centers for Environmental Information (NCEI). Climate at a Glance. 2020. Available online: https://www.ncdc.noaa.gov/cag/national/time-series/ (accessed on 23 August 2020).

33. Ahmed, M.; Haynes, K.; Taylor, M. Driving into floodwater: A systematic review of risks, behaviour and mitigation. Int. J. Disaster Risk Reduct. 2018, 31, 953-963. [CrossRef]

34. Diakakis, M. Types of Behavior of Flood Victims around Floodwaters. Correlation with Situational and Demographic Factors. Sustainability 2020, 12, 4409. [CrossRef] 
35. Paul, S.; Sharif, H.O.; Crawford, A.M. Fatalities Caused by Hydrometeorological Disasters in Texas. Geosciences 2018, 8, 186. [CrossRef]

36. McKenna, F.P.; Waylen, A.E.; Burkes, M.E. Male and Female Drivers: How Different Are They? Transport Research Laboratory: Workingham, UK, 1998; Available online: https://trid.trb.org/view/496586 (accessed on 13 July 2020).

37. Chen, L.H.; Baker, S.P.; Braver, E.R.; Li, G. Carrying passengers as a risk factor for crashes fatal to 16- and 17-year-old drivers. JAMA 2000, 283, 1578-1582. [CrossRef]

38. Mukherjee, F.; Singh, D. Detecting flood prone areas in Harris County: A GIS based analysis. GeoJournal 2019, 85, 647-663. [CrossRef]

39. Omranian, E.; Sharif, H.; Dessouky, S.; Weissmann, J. Exploring rainfall impacts on the crash risk on Texas roadways: A crash-based matched-pairs analysis approach. Accid. Anal. Prev. 2018, 117, 10-20. [CrossRef] [PubMed]

40. Sharif, H.; Hossain, M.; Jackson, T.; Bin-Shafique, S. Person-place-time analysis of vehicle fatalities caused by flash floods in Texas. Geomat. Nat. Hazards Risk 2012, 3, 311-323. [CrossRef]

41. Abdel-Aty, M.; Chen, C.L.; Radwan, A.E. Using Conditional Probability to Find Driver Age Effect in Crashes. J. Transp. Eng. 1999, 125, 502-507. [CrossRef]

42. Hamilton, K.; Demant, D.; Peden, A.E.; Hagger, M.S. A systematic review of human behaviour in and around floodwater. Int. J. Disaster Risk Reduct. 2020, 47, 101561. [CrossRef]

43. Coles, A.R.; Hirschboeck, K.K. Driving into Danger: Perception and Communication of Flash-Flood Risk. Weather. Clim. Soc. 2020, 12, 387-404. [CrossRef]

44. FEMA. Are you Ready? Guide; Federal Emergency Management Agency: Washington, DC, USA, 2004. Available online: https://www.fema.gov/pdf/areyouready/areyouready_full.pdf (accessed on 25 February 2020).

Publisher's Note: MDPI stays neutral with regard to jurisdictional claims in published maps and institutional affiliations. 